Caligrama, Belo Horizonte, v.19, n.2, p. 131-149, 2014

\title{
Marcadores discursivos e enunciação: uma possibilidade de debate sobre a elaboração discursiva da imagem de si e do outro
}

\section{Discourse markers and enunciation: a possible debate about the discursive elaboration of oneself and the other}

Ivani Cristina Silva Fernandes

Universidade Federal de Santa Maria (UFSM), Santa Maria, Rio Grande do Sul, Brasil. icrisifer@gmail.com

Resumo: O presente trabalho visa discutir a importância e as especificidades da atividade analítica e didática sobre os marcadores discursivos em português como língua materna e em espanhol como língua estrangeira para brasileiros. Para esta finalidade, pretendemos analisar um corpus composto por textos do gênero jornalístico, de tendência argumentativa, de alguns dos mais importantes jornais do Brasil, Espanha e Argentina. Baseados nessa análise, esperamos identificar os principais desafios ao enfocar os marcadores discursivos como eixo para refletir sobre questões tais como a construção do ethos e da alteridade em língua materna e estrangeira e as estratégias de persuasão a partir da retórica contrastiva, entre outras. Fundamentados na Linguística da Enunciação, área que reúne as principais teorias a partir das quais os pesquisadores refletem sobre fenômenos relacionados à enunciação, como nos trabalhos de Benveniste; e nos estudos pragmáticos e enunciativos sobre os Marcadores do Discurso, representados especialmente por Martín Zorraquino e Portolés, almejamos comentar o papel dos marcadores como guias de determinados efeitos de sentido que influenciam diretamente na construção do ethos e na percepção da alteridade no discurso. Tais construções e percepções podem seguir distintos percursos em língua materna e estrangeira, o que potencializa uma discussão sobre a relação entre forma e sentido na materialidade linguística, no português e no espanhol, enfocando a questão de como o sujeito se marca na língua. 
Palavras-chave: efeitos de sentido; ensino de português e de espanhol; enunciação; ethos; marcadores discursivos.

Abstract: The present paper aims at discussing the importance and specific aspects of analytical and didactic work on the discourse markers in Portuguese as a mother tongue and Spanish as a foreign language to Brazilians. In order to accomplish that, we intend to analyze a corpus composed of texts of journalistic genre and argumentative tendency, from some of the most important Brazilian, Spanish and Argentine newspapers. Through this analysis, we hope to identify the key challenges by focusing on the discourse markers as guidelines to reflect on issues such as the construction of ethos and otherness in the mother tongue and in a foreign language as strategies of persuasion from contrastive rhetoric, among others. Our theoretical basis is the Linguistics of Enunciation, which meets the main theories from which the researchers reflect on phenomena related to the enunciation as the Benveniste's works and Martin Zorraquino's and Portoles' studies about pragmatics and enunciative works on discourse markers. We aim to review the role of discourse markers as clue of specific effects of meanings that influence directly in the construction of ethos and in the perception of otherness in the discourse. Such constructions and perceptions may follow different pathways in the native language and foreign language, which strengthens a discussion about the relation between form and meaning in the linguistic materiality, in Portuguese and in Spanish, highlighting the way subject is marked in the language.

Keywords: meaning effects; teaching of Spanish and Portuguese; enunciation; ethos; discourse markers.

Recebido em 12 de agosto de 2014. Aprovado em 15 de dezembro de 2014.

\section{Introdução ${ }^{1}$}

Um dos temas mais frequentes no percurso dos estudos linguísticos se atrela à indagação de como o sujeito emerge da linguagem

\footnotetext{
${ }^{1}$ Esse trabalho foi apresentado parcialmente na modalidade de comunicação oral do III Colóquio Internacional de Marcadores Discursivos nas Linguas Românicas no Instituto de Estudos Linguísticos da UNICAMP, em 2013.
} 
e deixa suas marcas na materialidade da língua. Em outras palavras, desde a Antiguidade estamos enfrentando o desafio de entender a subjetividade na linguagem, de que maneira o homem se faz homem pela palavra e se concretiza na palavra.

Na tela textual trançada pelos mecanismos linguísticos, podemos observar os jogos entre o mesmo versus o outro, o igual versus o diferente, a identidade versus a alteridade. Em especial, na época atual, denominada por Bauman (2001) "modernidade líquida", as relações e as identidades aparecem como fluídas, instáveis e multifacetadas. E, evidentemente, tais características se revelam na materialidade linguística.

Em nossa sociedade, em que as concepções de "ser" e "consumir" estão intimamente vinculadas, Bauman (2009) destaca que:

a "identidade" agora compartilha o destino de outros equipamentos de vida: espera-se e prefere-se que ela, na falta de uma direção determinada definitiva, e não mais destinada a deixar atrás de si traços sólidos e indestrutíveis, seja fácil de ser fundida e passível de ser remodelada em diferentes formatos. Antes um "projeto para toda a vida", a identidade agora se transformou num atributo momentâneo. Uma vez planejada, não é mais "construída para durar eternamente": precisa ser montada e desmontada. Cada uma dessas duas operações aparentemente contraditórias tem a mesma importância e tende a ser igualmente absorvente (BAUMAN, 2009, p. 22).

Ao considerar que a identidade e, consequentemente, a alteridade, são processos em contínua (re)elaboração, é possível pensar que a noção aqui tratada se movimenta mais em termos de imagem do que em sua natureza concreta. Nesse sentido, ao tratar sobre as multiplicidades das imagens, é fundamental recordar a observação de Silva (2012, p.15) de que:

quando dizemos: 'isto é uma imagem ', queremos dizer que a imagem é, ou existe. Toda a questão está em entender esse modo de existência [...]. O filósofo [...] considera as imagens e a multiplicidade das aparências, mas seu objeto é atingir a unidade, isto é, a essência ou a realidade [...]; para o filósofo, essa multiplicidade de outros deve ser questionada como forma de busca da unidade do mesmo (SILVA, 2012, p. 15). 
Esse sucinto olhar filosófico tem como objetivo enfatizar a necessidade de entender como se dá a existência, a construção dos sujeitos em imagens discursivas, não tanto no sentido de buscar algo acabado, mas sim pensar nos efeitos de sentido únicos que se dão no momento da enunciação e são recuperados no enunciado que se atualiza pelo sujeito que o constrói e, no mesmo momento, é construído na palavra.

Se seguirmos o raciocínio de Bauman, percebemos que o indivíduo, mais que nunca, busca e necessita remodelar sua imagem constantemente, em cada discurso, de forma instantânea, guiado pelas circunstâncias socio-históricas instáveis. É um significar-se que se dá pelo fazer e desfazer dos jogos de imagem entre o "eu" e o "outro".

Esse processo enunciativo-discursivo implica uma articulação dos mecanismos linguísticos que, conforme cada rearranjo, tece uma rede de sentidos. É tal processo que deve surgir como desafio na busca de um ensino de língua, seja materna ou estrangeira, que prioriza a construção de uma reflexão linguística realmente significativa na vida dos discentes e professores envolvidos no processo de ensino.

Toda a materialidade linguística é relevante nessa ponderação. No entanto, no presente artigo, vamos dirigir nossa atenção a uma classe de elementos denominados marcadores discursivos, por acreditar que, apesar dos inúmeros trabalhos dedicados a tais mecanismos, ainda temos um caminho longo a percorrer quando tratamos de pensá-los a partir de uma perspectiva enunciativa. Essas unidades são polifuncionais pragmaticamente e possuem três funções: a) instituir conexão argumentativa; b) estabelecer conexão estrutural ou metadiscursiva; e c) enfatizar mecanismos de modalização. Além disso, essas estruturas auxiliam no esboço das marcas do sujeito e produzem vários efeitos de sentido.

\section{Posturas conceituais: noções de enunciação, sujeito e marcadores discursivos}

Nos últimos anos, o termo "enunciação" é encontrado com certa frequência nos trabalhos de vários campos referentes aos estudos sobre a linguagem, tais como Pragmática, Análise do Discurso e Linguística Textual, entre outros. No entanto, nem sempre encontramos explícito o que se entende por esse termo e suas implicações.

É nesse contexto que se desenvolve a Linguística da Enunciação que, segundo Flores e Teixeira (2005), é um campo que reúne uma série 
de teorias que focalizam a análise de fenômenos enunciativos, a partir de diferentes perspectivas, mas sempre baseadas nas ideias saussurianas.

Devido à pluralidade de estudos sobre a enunciação, também temos, por sua vez, uma variedade de noções relacionadas aos termoschave desse campo: enunciação e enunciado. Para os fins desse trabalho, decidimos destacar o conceito mais clássico sobre enunciação, o de Benveniste (BENVENISTE, 2006², p. 82), definido como o fenômeno pelo qual a língua é colocada "em funcionamento" por meio "de um ato individual de utilização", isto é, se transforma em um modo como o sujeito se enuncia e se constrói no contexto da imanência, da unicidade do fenômeno. Por sua parte, o enunciado é a manifestação da enunciação, o seu produto (FLORES et al., 2009a, p. 107).

É importante destacar, como o fez Fiorin (2005, p. 31), que o enunciado é a instância na qual o sujeito se revela e mostra suas marcas. Também é nessa instância que podemos analisar as articulações dos mecanismos linguísticos que formam a materialidade linguística. Em suma, é no enunciado que percebemos as marcas do sujeito e os efeitos de sentido dos marcadores do discurso.

A propósito, ao nos referirmos ao termo "sujeito", também devemos ter a mesma atenção recorrente aos termos polifuncionais. Basicamente, como aponta Schöpker (2010, p. 229), do ponto de vista filosófico, temos três tipos de sujeito: o lógico (o sujeito proposicional), o psicobiológico (o 'indivíduo concreto') e o metafísico (o eu da consciência, do espírito).

Do ponto de vista da Linguística, tampouco o quadro se apresenta conciliador, embora possamos fazer algumas correlações com as noções apresentadas pela Filosofia. Em linhas gerais, temos o sujeito psicobiológico (o sujeito falante da Pragmática), o sujeito enunciante / enunciador (o sujeito do enunciado na Linguística da Enunciação) e o sujeito discursivo (o sujeito assujeitado da Análise do Discurso no sentido pechêutiano). ${ }^{3}$

${ }^{2}$ Embora o artigo "O aparelho formal de enunciação" esteja em Problemas de Linguística Geral II, 1ª edição brasileira de 1989, Benveniste o publicou em 1970.

${ }^{3}$ Convém lembrar que tais esboços são traços gerais, posto que, dentro de cada campo teórico, a noção de sujeito varia conforme o autor e as diferentes teorias que tratam o assunto. Como exemplo, temos Ducrot que concebeu três definições para o termo "enunciador" conforme o momento em que se encontrava o seu estudo. Ver FLORES (2009a). 
Considerando que nosso ponto de vista é de natureza enunciativa, entendemos o sujeito atrelado ao conceito de enunciador, figura que deixa suas marcas no enunciado, lembrando que a Linguística da Enunciação não enfatiza o estudo do sujeito em si, mas a existência de suas marcas no enunciado, o que, por sua vez, implica efeitos de sentido.

Essa breve discussão sobre o sujeito implica questionarmos a questão do ethos discursivo, conceito, de origem aristotélica, empregado na Linguística da Enunciação e na Análise do Discurso. Tal noção pode designar a imagem discursiva de si, construída pelo próprio locutor (AMOSSY, 2005, p. 23). Além disso, esse conceito também se vincula ao perfil de um enunciador, ao tom enunciativo e à cena de enunciação (espaço instituído por um gênero e constituído por um discurso).

Por último, convém apresentar o conceito de marcadores discursivos presente nesse trabalho. Seguindo os preceitos de Martín Zorraquino e Portolés (1999), os marcadores são unidades linguísticas invariáveis, não exercem uma função sintática no marco da predicação oracional (são elementos marginais na oração) e orientam inferências que se realizam na comunicação de acordo com as propriedades morfossintáticas, semânticas e pragmáticas. Dessa forma, conforme o seu significado procedimental, podemos ainda classificá-los em estruturadores da informação, conectores, reformuladores, operadores discursivos e marcadores conversacionais ${ }^{4}$.

Como já havíamos evidenciado em Fernandes (2012), considerando que nossas amostras pertencem à modalidade escrita, demarcamos os limites do enunciado a partir de aspectos relacionados aos sinais ortográficos e prosódicos. Portanto, baseados em Domínguez García (2002), os marcadores são estruturas que, frequentemente, se localizam em posição inicial do enunciado, após ponto, ponto e vírgula, ou dois pontos (quando estes últimos equivalem ao ponto) e na posição de inciso e final do enunciado. Essas particularidades assinalam a sua independência entonativa, o que garante a mobilidade de tais elementos no enunciado. Cabe destacar que o emprego dos sinais de pontuação,

\footnotetext{
${ }^{4}$ Cabe lembrar que as terminologias, as classificações e as subclassificações dos marcadores são ainda objetos de inúmeras discussões teóricas e, portanto, não constituirão uma questão amplamente contemplada neste artigo. Contudo, os parâmetros classificatórios expostos aqui se baseiam nos trabalhos de Martín Zorraquino e Portolés (1999) e Fernandes (2005).
} 
mais que uma questão normativa, obedece também a características estilísticas, referentes a como o sujeito organiza o enunciado.

Ao observar as três noções basilares do nosso texto - enunciação, sujeito e marcadores discursivos - aqui apresentadas, notamos que os marcadores do discurso podem auxiliar na reflexão sobre alguns fenômenos enunciativos, em especial no que concerne à imagem do sujeito, uma vez que tais elementos, ao relacionarem enunciados, produzem determinados efeitos que se refletem no sujeito que emerge do enunciado.

\section{Uma proposta de análise: os sujeitos emergentes na materialidade de suas línguas}

Observamos que, comumente, se analisam os marcadores discursivos por meio de um viés pragmático, enfocando as questões de estratégia do locutor e as características coesivas de conexão. Com certeza esse viés é necessário e continua contribuindo para que possamos entender algumas características dos marcadores. No entanto, incluir um ponto de vista enunciativo nas análises permite discutir as possibilidades dos marcadores, combinados com outros elementos linguísticos, de produzir determinados efeitos de sentido que revertam na configuração do enunciador e de seu ethos.

Com a finalidade de discutir a proeminência de uma visão enunciativa nas análises do papel dos marcadores discursivos, apresentamos o estudo de algumas amostras de textos do gênero "Carta do leitor" Nossa escolha recaiu sobre esse gênero devido ao fato de que queríamos trabalhar com textos de tendência argumentativa de extensão reduzida, mas que implicasse precisão no emprego dos mecanismos linguísticos. Assim, vimos que o gênero "Carta do leitor" preenchia esses requisitos.

\footnotetext{
${ }^{5}$ Essas amostras fazem parte de um corpus constituído por 90 textos do gênero "Carta do leitor", ainda em fase de análise, publicados nos jornais (na sua versão digital do mês de abril de 2013) O Estado de S. Paulo (Brasil), El País (Espanha) e La Nación (Argentina), com trinta amostras para representar cada periódico. Os parâmetros metodológicos seguem um estudo anterior (FERNANDES, 2005), no qual encontramos 77 marcadores no jornal El País e 53 no O Estado de S. Paulo, seguindo a classificação de Martins Zorraquino e Portolés (1999), ou seja, estruturadores da informação, conectores, operadores argumentativos, reformuladores e marcadores conversacionais e suas respectivas subcategorias. No atual estudo, vemos a proeminência de marcadores, em especial de conectores e reformuladores, nos textos em espanhol com relação ao português.
} 
Dessa forma, baseando-nos na definição de Costa (2008, p. 50), concebemos a "Carta do leitor" como um texto "geralmente de opinião (argumentativa)" que "circula em jornais e revistas, já que o leitor a envia para manifestar seu ponto de vista sobre matérias que leu". Sua natureza argumentativa, envolvida em determinada prática social, permite que, nesse gênero, se observe um emprego preciso dos mecanismos linguísticos no sentido de guiar o interlocutor a inferências mais ou menos particulares, destacando variados efeitos de sentido em espaço físico de dimensão específica.

Outro aspecto fundamental ao tentar inter-relacionar marcadores e imagem discursiva do sujeito é centrar na tendência argumentativa do gênero. Ao tentar traçar a noção de argumentação, em um sentido mais pragmático e "utilitarista", notamos que existe uma tendência em considerá-la como um conjunto de estratégias e procedimentos que permitam debater ou deliberar sobre determinada questão dentro dos padrões de civilidade e respeito com os demais interlocutores.

No entanto, a partir do ponto de vista enunciativo, concebe-se a argumentação como uma "coconstrução enunciativo-discursiva", na qual o locutor deve refletir sobre a perspectiva do outro, considerando-a na articulação dos argumentos. Tal ação tem como objetivo elaborar discursivamente o ponto de vista do locutor, tendo em vista um contexto em que há uma multiplicidade de faces e vozes identitárias. Portanto, a argumentação não se restringe aos processos de convencer / persuadir ${ }^{6}$ o interlocutor por meio de articulações lógicas e retóricas.

Como guia metodológico, nos baseamos pelos princípios do paradigma indiciário ginzburguiniano, que se fixa em alguns indícios no texto que podem levar o analista a traçar determinado fenômeno linguístico. Assim, se enfatiza "um saber de tipo veneratório", determinado pela "capacidade de, a partir de dados aparentemente negligenciáveis, remontar a uma realidade complexa não experimentável diariamente" (GINZBURG, 1989, p. 152).

No presente artigo, consideramos os marcadores como indícios. A partir da definição da classificação discutida por Martin Zorraquino

\footnotetext{
${ }^{6}$ Para os fins desse trabalho, entendemos como "convencimento" o processo baseado em argumentos referentes ao âmbito dos fatos, dados e elementos plausíveis à realidade. Por outro lado, a "persuasão" se refere ao processo baseado em argumentos que objetivam provocar algum tipo de "emoção ou sentimento" ao interlocutor.
} 
e Portolés (1999) e Fernandes (2005), identificamos tais elementos. Posteriormente, analisamos as suas principais funções procedimentais no texto e, a seguir, suas possíveis articulações com outros elementos linguísticos e seus efeitos enunciativo-discursivos que podem influenciar a constituição da imagem do locutor.

Desse modo, para os fins deste artigo, trazemos amostras representativas da presença de algumas categorias de marcadores e seus efeitos de sentido, retiradas dos três jornais (dois em língua espanhola, um em língua portuguesa). Acreditamos que a discussão sobre tais amostras possa orientar uma reflexão sobre as potencialidades e problemas de uma visão enunciativa no estudo dos marcadores do discurso, em especial quando tratamos do ensino de língua materna e estrangeira, no nosso caso, português brasileiro e espanhol.

Ao observar o corpus constituído, temos que destacar algo evidente, mas não sempre considerado nas análises: a importância de identificar as relações entre efeitos de sentido dos marcadores com outras estruturas da língua. Por exemplo, percebemos uma tendência de presença de alguns marcadores juntamente com as perguntas retóricas com papel relevante no texto. Também se apresentam os casos que se referem à força argumentativa amplificada e/ou reduzida de determinado marcador devido ao uso da pontuação (ou à ausência da mesma). Outra tendência identificada é a da polifuncionalidade de alguns marcadores, como se registra nos estudos pragmáticos, mas que reconhecemos como efeitos de alguns mecanismos em enunciados nos quais emergem efeitos de sentido relevantes para o texto.

Iniciamos nossos comentários analíticos apresentando um exemplo mais "tradicional" do emprego de um conjunto de marcadores em textos de tendência argumentativa. Cabe alertar que, para facilitar o processo analítico, negritamos os marcadores do discurso.

Publicado no jornal El Pais, de 18 de abril de 2013, a carta do leitor enfoca o tema da postura da sociedade diante de atentados considerados terroristas. 


\section{Una sociedad conmocionada ${ }^{7}$}

FRANCISCO JAVIER ESPAÑA MOSCOSO La Navata-Galapagar. 18 ABR 2013 00:00 CET

Se hace evidente pensar que los autores del atentado de Boston buscaban sembrar de víctimas la ciudad y así ha sido; pero después de la lección aprendida en los atentados del 11-S, 11-M, 11-J, etcétera, debemos hacer una lectura fría.

¿Qué hemos aprendido de otros actos de igual magnitud? Que, además de lo vulnerables que somos, algunos países con intereses muy concretos han vertebrado su política geoestratégica al calor de la venganza en caliente, aprovechando que la sociedad estaba sumida en el shock.

Por un lado, si la autoría y las connivencias del atentado llegaran hasta el famoso eje del mal, y ya sabemos cómo funciona esto, la mal llamada "comunidad internacional' tendría motivos para aplastar a Corea del Norte, empeñada aparentemente en provocar al resto del mundo, e incluso estaría mucho más cerca una intervención abierta en Siria: sin olvidar por supuesto a Irán, que para algunos es la fuente de todo el terrorismo internacional.

Por otro lado, y a la vista de las sospechosas elecciones presidenciales de Venezuela, EEUU podría despejar sin ambages su patio trasero, apoyando descaradamente un cambio político al viejo estilo bananero de los sesenta y setenta del siglo pasado. Y no es menos importante recalcar que en EEUU algunos atentados son exclusivamente domésticos y se ejecutan preferentemente cuando gobierna un presidente demócrata con gran proyección y mejor popularidad. Basta solo con recordar el de Oklahoma City de 1995, siendo presidente Bill Clinton.

Y es que a estas alturas, con una sociedad conmocionada, nada es lo que parece.Francisco Javier España Moscoso.

Nesse exemplo, vemos duas das categorias mais comuns entre os marcadores: os conectores (relacionam semântica e pragmaticamente dois ou mais enunciados, guiando inferências produzidas do conjunto enunciativo) e os estruturadores da informação (organizam informativamente o discurso, ordenando a dinâmica entre tópico e comentário).

O conector contra-argumentativo "pero" articula contraposições de natureza adversativa e concessiva entre enunciados. No entanto, aqui, tal conector não introduz necessariamente uma relação adversativa ou

\footnotetext{
${ }^{7}$ Disponível em: <http://elpais.com/elpais/2013/04/17/opinion/1366219532_419509. html> Acesso em 12 ago. 2014.
} 
concessiva, mas sim "convoca" o interlocutor a seguir o seu raciocínio, supostamente mais objetivo ([...] debemos hacer uma lectura más fria), depois de apresentar o quadro ao qual se atém ([...] la lección aprendida trás los atentados [...]). Outro elemento que reforça tal hipótese é o uso do verbo "deber" na $1^{\text {a }}$ pessoa do plural, o qual enfatiza o tom instigante desse ethos discursivo que se esboça; além do uso ambíguo do ponto e vírgula, que permite uma conexão que mantém a veiculação entre o fato atual e o pano de fundo da tese do enunciador, ao mesmo tempo em que destaca o início do enunciado que contém explicitamente a voz do locutor, sugerindo a sua tese.

Já no caso do conector aditivo " $y$ " no último enunciado, tal elemento não só introduz a conclusão, reforçando a tese (já esboçada no título), mas também destaca um enunciado curto, incisivo e contundente, com o apelo de uma frase feita bem presente no discurso da sociedade atual ([...] nada es lo que parece).

Os demais estruturadores da informação, da categoria dos ordenadores ("por un lado", "por otro") e o conector aditivo ("y") cumprem o seu papel argumentativo de forma modélica, isto é, introduzem enunciados marcados espacialmente, que possuem informações complementares e agregam um enunciado que contém um argumento secundário. Contudo, se formos dedicar-lhes um olhar enunciativo, tentando estabelecer conexões entre os seus efeitos e a macro estrutura textual, entre os efeitos de sentido e a construção de um ethos do enunciador, podemos lançar como hipótese que eles contribuem para estabelecer uma organização explicitamente marcada, o que ajuda a conferir um tom didático e sistemático ao ethos discursivo, quando combinamos esse dado com outros aspectos linguísticos do texto, tais como tipos de estruturas sintáticas, escolha lexical e uso de determinados sinais de pontuação, entre outros.

No exemplo que apresentamos a seguir, observamos mecanismos similares que estão presentes na modalidade escrita do português brasileiro, mas que revelam outra forma de "significar" do sujeito do enunciado. Nessa carta do leitor, publicada no dia 19 de abril de 2013, n'O Estado de S. Paulo, o locutor comenta o descrédito das instituições brasileiras. 


\section{VAMOS MAL ${ }^{8}$}

São muito estranhos os "zum zum zums" dos últimos dias no Brasil. Primeiro, a filha de um ministro do STF que trabalha em escritório de advocacia com casos sendo julgados no próprio STF e eventual participação do ministro pai no julgamento das ações. Não que haja favorecimentos, mas é no mínimo extremamente delicada coisa desse tipo. Em segundo lugar, boatos dão conta de informações privilegiadas aos eventuais "peixes" do ministro Mantega quanto às elevações de taxas de juros no mercado futuro. Fatos como esses, se verdadeiros, trazem um enorme desgaste e, pior do que isso, causam desânimo e descrédito geral. Assim, tenham certeza, vamos mal, mas muito mal mesmo.

José Piacsek Neto bubapiacsek@yahoo.com.br

Avanhandava

A tese, que inicialmente é sugerida no sintagma verbal do título para depois se tornar mais concreta ao decorrer do texto, está realmente destacada apenas no último enunciado, introduzido pelo conector "assim”. Santos Río (2003, p. 201) elenca alguns valores da partícula "assim" (asi), destacando a sua natureza causal característica da oralidade. No entanto, em alguns contextos específicos - nos meios de comunicação, com tom ensaístico - tal conector adquire um valor argumentativo-conclusivo (SANTOS RÍO, 2003, p. 203), permitindo apresentar circunstâncias explícitas por meio de causas e de conjecturas categóricas ou conclusivas.

Na presente amostra, o locutor reforça ainda mais o tom taxativo por meio da oração na forma imperativa do inciso ("tenham certeza"), que confere confiança ao locutor sobre o que está sendo dito. Além disso, é empregado o conector adversativo "mas", que explicita o caráter pleno, hiperbólico e coerente da qualificação do que foi mencionado antes, como observa Santos Río (2003, p. 502). Este efeito é amplificado pelo uso dos advérbios de intensidade "muito" e "mesmo".

Por outro lado, os ordenadores "primeiro" e "em segundo lugar", além de organizarem o surgimento de argumentos dependentes, de natureza factual, auxiliam no estabelecimento de um tom mais direto e categórico de expor os enunciados que contêm os argumentos. Convém

${ }^{8}$ Disponível em: <http://www.estadao.com.br/noticias/impresso,forum-dosleitores, 1022862,0.htm> Acesso em 12 ago. 2014. 
observar que tais enunciados têm a estrutura sintática caracterizada por elipses, sintagmas e orações justapostos e ausência de determinantes, o que potencializa o tom categórico de modalidade oral.

Queremos ainda destacar que, em uma comparação entre esses dois textos, temos marcadores semelhantes, com significados processuais e orientações argumentativas também semelhantes, porém com efeitos enunciativos um pouco diversos que auxiliam elaborações diferentes do ethos, uma vez que um grupo enfatiza a organização dos dados e o outro a contundência e dependência entre os acontecimentos. Tal dado é de extrema relevância quando o agregamos em uma análise enunciativodiscursiva, ainda mais no âmbito de uma retórica contrastiva.

A próxima amostra, publicada no jornal La Nación, em 11 de abril de 2013, se refere à necessidade de controlar o destino lícito das doações em contextos de catástrofes.

\section{EL DESTINO DE LAAYUDA ${ }^{9}$}

Muchas veces hemos condenado los males de nuestra idiosincrasia: la soberbia, la prepotencia, la falta de seriedad y responsabilidad. Pero hay gestos que nos redimen. Y se dan cuando ocurren humillaciones a seres indefensos, robos, muertes o catástrofes naturales. Allí sale a luz la solidaridad y el amor al prójimo.

La tormenta desatada hace días en la ciudad de La Plata lo ha puesto de manifiesto. Desde el seno del pueblo ha surgido la ayuda anónima y espontánea, sin paternalismo político que la manipule o degrade. Ahora bien, ¿quiénes se hacen responsables -además de instituciones serias y confiables- de recibir tan generosa contribución -colchones, abrigos, calzados, remedios- para asegurar que llegue a los verdaderos damnificados? ¿Quiénes organizan con criterio de equidad, la honesta entrega de tan descomunal envío?

Ya han ocurrido, entre los argentinos, hechos bochornosos de donaciones que no llegaron a destino por aquello de la viveza criolla de usurpar la ayuda y darle un destino contrario al gesto de solidaridad.

Hay que controlar la tarea del reparto honesto y oportuno, para que nuestros hermanos de La Plata no se vean engañados por "comedidos sin escrúpulo". La autoridad provincial y la nacional deben proporcionar a la ciudadanía un informe detallado y preciso del real destino de esta gigantesca ayuda. Dios lo quiera.

René Vargas Vera

DNI 6.949.874

${ }^{9}$ Disponível em: <http://www.lanacion.com.ar/1571481-cartas-de-lectores $>$ Acesso em 12 ago. 2014. 
Além dos empregos de alguns conectores já aludidos, como "pero" e " $y$ ", nos interessa destacar a existência de perguntas retóricas introduzidas por conectores - no presente caso, o conector contraargumentativo "ahora bien" que, pragmaticamente, introduz uma informação de considerável proeminência argumentativa.

De acordo com Santos Río (2003, p. 183), tal conector possui dois valores. O primeiro é o adversativo restritivo forte, pelo qual se introduz uma informação nova ou um ato ilocutivo que supõe, em alguma medida, orientação argumentativa contrária ao que o enunciado anterior sugere. Por outra parte, o segundo valor é o "pseudoadversativo", que insere uma premissa assertiva e informativa que antecipa e prepara a aproximação de uma conclusão. Também se chegou a considerá-lo como um elemento metadiscursivo, uma vez que organiza a introdução das perguntas retóricas.

Podemos pensar que tal conector tem papel enunciativo fundamental, pois coloca em evidência a posição do enunciador diante da construção das imagens dos interlocutores, além de destacar a contundência do argumento. É possível formular essa hipótese, se aceitamos que o papel das perguntas retóricas é o de invocar a figura do interlocutor como sujeito pensante, enfatizando a coenunciação. Também devemos considerar que um dos principais argumentos do locutor não aparece explicitamente, mas é construído conjuntamente no processo de enunciação. ${ }^{10}$

Como última amostra apresentada neste trabalho e que exemplifica a problemática dos efeitos enunciativos na construção da imagem do sujeito, escolhemos um texto de $O$ Estado de S. Paulo, publicado em 19 de abril de 2013, cujo tema se refere à maioridade penal.

${ }^{10}$ Convém explicitar que foi recorrente no nosso corpus esse tipo de articulação linguística "conector contra-argumentativo + pergunta retórica que esboça a tese ou argumento relevante", em especial com os conectores "pero" ou "mas". 


\section{MAIORIDADE PENAL ${ }^{11}$}

Finalmente uma iniciativa para romper a letargia a respeito da legislação penal: Alckmin vai a Brasília... Claro que mexer com o Estatuto da Criança e do Adolescente é complicado, pela ideologia e pela cultura de vitimização vigente. Claro que falta espaço para encarcerar os assassinos. Claro que há cláusulas pétreas atrapalhando. Mas nada disso é desculpa para manter o descalabro ridículo de considerar inimputável indivíduos que têm plena consciência de seus atos, e votam para presidente, só por serem "di menor". Basta de impunidade. Basta de favorecer o bandido que mata o bom cidadão. Enquanto se permitir a matança não haverá esperança... O País necessita urgentemente de uma Justiça que seja justa!

GILBERTO DIB

gilberto@dib.com.br

São Paulo

No exemplo agora apresentado, além da presença do conector contra-argumentativo "mas", cujo efeito já foi aludido nos exemplos anteriores, destacaremos as particularidades dos estruturadores da informação e marcadores conversacionais.

O estruturador "finalmente", em geral concebido como um clássico metadiscursivo, introduz o fragmento final de uma argumentação, após uma extensa série de argumentos ou indica a ordem do enunciado ou do ato enunciativo em uma sequência (SANTOS RÍO, 2003, p. 75). Contudo, notamos que tal ordenador se localiza no início do texto, em que não há nenhuma sequência prévia, mas sim a pressuposição de uma série de atos enunciativos. Isso indicaria que esse marcador se refere muito mais à postura do enunciador diante da informação expressa, o que, consequentemente, imprime um tom de espontaneidade, exaustão, impaciência e ansiedade. Portanto, a questão de polifuncionalidade não se refere apenas às particularidades pragmáticas e metadiscursivas do marcador, mas sim aos seus efeitos de sentido na construção do processo coenunciativo e da constituição de um ethos.

Já a presença dos marcadores conversacionais implica, muitas vezes, efeitos de sentido importantes, posto que o fato de elementos

${ }^{11}$ Disponível em: <http://www.estadao.com.br/noticias/impresso, forum-dosleitores, 1022862,0.htm> Acesso em 12 ago. 2014. 
característicos da modalidade oral estarem localizados em textos de modalidade escrita indicaria efeitos que vão além do domínio da Pragmática ou da Linguística Textual. Aliás, a própria definição de marcadores epistêmicos - elementos que sinalizam a maneira como o enunciador aborda o enunciado - implica a pertinência de uma perspectiva enunciativa sobre o objeto. No exemplo em questão, o marcador "claro (que)" poderia enfatizar, nesse contexto, a evidência da informação, veiculando as circunstâncias implícitas ou as inferências, supostamente compartilhadas com os interlocutores, ou seja, o seu caráter consabido e incontestável.

De forma direta, esse último ponto incide na concepção dos interlocutores no texto. Por meio de uma estrutura caracterizada pelo paralelismo sintático, o marcador "claro (que)" insere antecipadas refutações a sua tese, configurando um movimento concessivo e modalizado, para que, em seguida, introduza sua consideração categórica com relação às refutações anteriores, iniciando, portanto, um movimento contra-argumentativo. Cabe destacar que os próximos enunciados estão caracterizados pelo paralelismo sintático do sintagma basta de [...], pelas reticências e ponto de exclamação, que imprimem um tom categórico e reivindicativo.

Essas estruturas sintáticas, combinadas, potencializam o protagonismo dos marcadores, pois ajudam a exemplificar como os mecanismos linguísticos se articulam para esboçar um ethos do enunciador e seus diversos efeitos, possibilitando um efetivo trabalho a partir da subjetividade na linguagem.

Quando observamos algumas definições sobre estruturas consideradas como marcadores do discurso, percebemos que há aspectos vinculados aos processos enunciativos, em especial à (co)construção textual realizada pelas vozes que se articulam no discurso. Seria possível que, com o aumento de análises que explorassem o viés enunciativo no emprego dos marcadores, houvesse algumas mudanças referentes à terminologia, às classificações e às características dos marcadores, uma vez que ainda vemos certa instabilidade ligada à noção dessa categoria.

Além do vinculo entre definição da categoria de marcadores e efeito enunciativo desses elementos, poderíamos citar outro campo frutífero para continuar a explorar os elos entre enunciação e marcadores: o ensino de língua materna e estrangeira. A identificação e a discussão sobre os possíveis efeitos de sentido dos marcadores em um texto e na constituição de um ethos, em línguas distintas, poderiam transformar-se em um eixo 
para iniciar um questionamento sobre como "forma e sentido" se unem, a partir de diferentes visões teóricas, em especial as pragmáticas, as cognitivas e as enunciativo-discursivas. Como vimos insistindo em nossos últimos trabalhos (FERNANDES, 2010, 2011, 2012), as análises dos marcadores do discurso no âmbito do ensino não devem limitar-se apenas ao seu aspecto de coesão sequencial, papel estrutural importante mas redutor, quando considerado isoladamente. Mais que isso, o estudo de marcadores, no contexto das análises retórico-contrastivas, não deve centrar-se em possíveis equivalências mais ou menos literais, pois, como demonstramos, cada marcador assume efeitos de sentido diversos que influenciam a configuração do enunciador, o qual, por sua vez, emerge especificamente em cada texto, o que evidencia modos idiossincráticos de enunciar e significar conforme a língua. Devemos perceber os modos díspares de nos fazer sujeitos na língua materna e na língua estrangeira. Esse é um ponto fundamental no ensino de línguas em várias etapas do percurso de formação institucional, seja ele o nível fundamental, médio ou superior.

É evidente que a ênfase na questão enunciativa-discursiva nas abordagens teórico-didáticas sobre os marcadores possivelmente requer novos estudos, não só por parte dos pesquisadores da área como também dos professores de língua. O conhecimento deve renovar-se e circular em todos os âmbitos, provocando questionamentos e reflexões.

\section{Considerações finais}

Como palavras finais, gostaríamos de voltar a alguns pontos que vimos enfatizando neste e em outros trabalhos no que concerne às relações entre estudos sobre os marcadores discursivos, perspectiva enunciativa e construção discursiva da imagem do sujeito na concretude da língua.

Em primeiro lugar, apesar da relevância dos fatores cognitivos, pragmáticos e estruturais dos marcadores (inclusive porque não se pode negligenciá-los), acreditamos que, no caso de estudos ligados à Linguística Enunciativa, devem-se enfatizar os fatores enunciativodiscursivos ligados aos marcadores, posto que esse olhar poderia ampliar as análises desses elementos, consolidando-os como uma categoria e permitindo novos esboços para seu tratamento analítico e didático.

Em segundo lugar, não se deve chegar ao extremo de supervalorizar o papel isolado dos marcadores no enunciado. Observamos que tais mecanismos sempre estão acompanhados de outros índices 
linguísticos, tais como: aspectos morfossintáticos dos elementos linguísticos, pontuação, propriedade semântica de alguns termos, entre outros. É importante observá-los em seu conjunto, entre outras unidades da mesma categoria e/ou de outras diversas.

Em terceiro lugar, são os seus empregos contextuais e incomuns que se transformam em índices enunciativos que norteiam, por sua vez, os efeitos de sentido pelos quais o sujeito se marca. Tal aspecto deve ser considerado tanto na elaboração de uma terminologia e classificação mais homogênea quanto nas discussões sobre abordagens didáticas desses elementos no seu ensino em língua materna e estrangeira.

Por último, analisados em conjunto com outros mecanismos, os marcadores são elementos basilares para refletirmos sobre as características de um ethos do enunciador que vai se constituindo na materialidade linguística. Além de guiar inferências do ponto de vista cognitivo, os marcadores orientam formas de dizer que configuram a presença do sujeito no enunciado e a importância da subjetividade na linguagem.

Em suma, esperamos que as questões aqui levantadas promovam discussões produtivas que contribuam para um ensino de língua mais significativo e para a própria conscientização do falante para os desafios e as belezas inerentes no ato tão cotidiano e tão singular do homem ao fazer-se humano na e por meio da linguagem, como já nos recordavam os ensinamentos benvenistianos.

\section{Referências}

AMOSSY, R. (Org.). Imagens de si no discurso: a construção do ethos. São Paulo: Contexto, 2005.

BAUMAN, Z. A arte da vida. Rio de Janeiro: Jorge Zahar Editora, 2009.

BAUMAN, Z. Modernidade líquida. Rio de Janeiro: Jorge Zahar Editora, 2001.

BENVENISTE, E. Problemas de linguística geral II. 2 ed. São Paulo: Pontes, 2006.

COSTA, S. R. Dicionário de gêneros textuais. Belo Horizonte: Autêntica, 2008. DOMÍNGUEZ GARCÍA, M. N. La organización del discurso argumentativo: los conectores. Salamanca: Ediciones Universidad de Salamanca, 2002. 
FERNANDES, I. C. S. A perspectiva sobre a construção do sujeito na argumentação: uma visão enunciativa no ensino de E.L.E. In: VI Seminário Nacional sobre Linguagem e Ensino, 2010, Pelotas, Universidade Católica de Pelotas.

FERNANDES, I. C. S. Consideraciones sobre la lingüística de la enunciación y la gramática de texto en las clases de E.L.E. In: XVI Congresso Brasileiro de Profesores de Espanhol, Niteroi, UFF, 2011.

FERNANDES, I. C. S. Los marcadores discursivos a partir de una perspectiva retórico-enunciativa: cómo los efectos de sentido surgen en la lengua. In: II Coloquio Internacional Marcadores del Discurso en Lenguas Románicas: un enfoque contrastivo, 2012, Buenos Aires, Actas eletrónico. Disponível em: <http://www.coloquiomarcadores.com.ar/archivos/Actas II_Coloquio_internacional_marcadores.pdf >. Acesso em 12 jul. 2014.

FERNANDES, I. C. S. Los marcadores discursivos en la argumentación escrita: estudio comparado en el español de España y en el portugués de Brasil. Salamanca: Ediciones Universidad de Salamanca, 2005. (Colección Vítor). 1 CD-ROM.

FIORIN, J. L. As astúcias da enunciação: as categorias de pessoa, espaço e tempo. 2. ed. São Paulo: Ática, 2005.

FLORES, V. N. et al. Dicionário de linguística da enunciação. São Paulo: Contexto, 2009a.

FLORES, V. N. et al. Enunciação e gramática. São Paulo: Contexto, 2009b.

FLORES, V. N.; TEIXEIRA, M. Introdução à linguística da enunciação. São Paulo: Contexto, 2005.

MARTÍN ZORRAQUINO, M. A.; PORTOLÉS LÁZARO, J. Los marcadores discursivos. In: BOSQUE, I.; DEMONTE, V. (dirs.) Gramática descriptiva del español. Madrid: Espasa, 1999. V. 5, p. 40514213.

SANTOS RÍO, L. Diccionario de partículas. Salamanca: Luso-Española, 2003.

SCHÖPKER, R. Dicionário filosófico: conceitos fundamentais. São Paulo: Martins Fontes, 2010.

SILVA, F. L. O outro. São Paulo: Martins Fontes, 2012. 
